This is the version of the article accepted for publication in Journal of Financial Markets published by Elsevier: https://www.journals.elsevier.com/journal-of-financial-markets/

Accepted version downloaded from SOAS Research Online: http://eprints.soas.ac.uk/30019

published under: https://creativecommons.org/licenses/by-nc-nd/3.0/

\title{
Too much of a good thing?
}

\section{Speculative effects on commodity futures curves}

\author{
Sophie van Huellen* \\ *SOAS University of London, Thornhaugh Street, Russell Square, London WC1H 0XG.
}

Email: sv8@ soas.ac.uk, Tel.: +44(0) 2078984543

\begin{abstract}
The increasing inflow of index traders into commodity futures markets has been linked to anomalies in futures curves. At the same time, these investors have been welcomed as liquidity providers. In this paper, I reconcile the apparent dissent. Using factor decomposition, I show (a) that index and hedging positions have offsetting effects on futures curves, and (b) index positions are associated with upward sloping, peaked futures curves, and occasionally wave-like shapes linked to roll effects. These findings suggest that index traders are liquidity providers but can become too much of a good thing if exceeding hedgers' demand for a counterparty.
\end{abstract}

JEL classification: G13, G14, Q02, Q14

Keywords: financialization; futures curve; speculation; soft commodities; term structure. 


\section{Introduction}

Commodity markets have become increasingly popular among investors since the early 2000s, when deregulation of U.S. commodity futures markets opened new opportunities for institutional investors and fund managers alike. As a result, the number of commodity contracts traded at derivative markets quadrupled within less than a decade. A vivid debate arose around the possible implications of this "financialization" of commodity futures markets for price discovery and risk management. Financialization in this context is understood as the increasing presence of non-traditional investors in commodity derivative markets using novel trading strategies and instruments such as commodity indices.

Critiques of this development link the growing presence of index traders in commodity futures markets to increases in price levels, volatilities, and comovements, as well as market anomalies such as non-convergence and inflated calendar spreads (e.g., Masters, 2008; U.S. Senate Subcommittee, 2009). Others welcome the presence of index traders as they provide liquidity and ease hedging pressure (e.g., Sanders et al., 2010). Recent studies have formalized some of the suggested effects of index trading on price discovery (e.g., Brunetti and Reiffen, 2014; Hamilton and Wu, 2014; Basak and Pavlova, 2016). However, the empirical literature remains divided over both the presence and the strength of this financialization effect. See Fattouh et al. (2013), Irwin (2013), and Cheng and Xiong (2014) for literature reviews.

Most researchers have attempted to identify an excess in price levels, volatilities, and comovements beyond what is explained by market fundamentals. Identifying the extent to which a price series moves against fundamentals is empirically challenging as fundamental variables are often latent and price data noisy. In this paper, I contribute to the debate, while focusing on commodity markets' term structure. I argue that an analysis of price differentials such as market 
basis or calendar spreads will more clearly identify financialization effects. Since pairs of price series are driven by the same commodity-specific fundamentals, the difference in level and variability can be attributed to factors that are specific to the commodity contract, including different compositions of traders.

Similar considerations have motivated other researchers to investigate calendar spreads and market basis in the context of the financialization debate (e.g. Irwin et al., 2011; Mou, 2011; Brunetti and Reiffen, 2014; Van Huellen, 2018). In contrast to previous studies that rely on calendar spreads for an analysis of the market term structure (e.g., Irwin et al., 2011; Brunetti and Reiffen, 2014), I recognize that calendar spreads are unable to capture non-linear shapes of futures curves such as bumps or waves, which have been theoretically linked to index investment. To alleviate this shortcoming, I propose a factor decomposition method developed by Nelson and Siegel (1987) and extended by Diebold and Li (2006) to capture the often non-linear shapes of the commodity futures curve.

Based on the two-period equilibrium pricing model proposed by Brunetti and Reiffen (2014), I derive hypotheses that are testable with the above-mentioned factor decomposition methods. In particular, I hypothesize that hedging and index positions have inverse and offsetting effects on the shape of the futures curve and refer to these effects as hedging pressure and index pressure. Hedging pressure exists if hedgers' short positions exceed index traders' long positions so that other speculators are required as liquidity providers and vice versa. While index pressure is associated with upward sloping (normal) and peaked futures curves, hedging pressure is associated with downward-sloping (inverted) and U-shaped futures curves. Further, index pressure is associated with occasionally wave-like shapes linked to roll-effects. 
These hypotheses are tested for three soft commodity markets: cocoa, coffee, and cotton. All three commodities are traded at the Commodity Market Exchange (CME) with relatively long observed future curves, trading up to 10 or more contracts spanning 24 months simultaneously. These markets have been studied less in the context of the financialization debate as they have seen less investment by index and other non-traditional traders compared to grains, energy, and metals. However, the moderate presence of index traders provides for evaluating index pressure alongside hedging pressure effects. This analysis would be impossible in grain markets where index positions have consistently outweighed hedging positions since the early 2000s. Further, their relatively long futures curve and the availability of storage data provides for robust empirical analysis.

Findings support the hypotheses posed above, whereby the strength of index pressure effects varies with the weight of index traders in the respective markets. In light of these findings, I argue that, while index traders ease hedging pressure by acting as liquidity providers, index positions, if exceeding hedgers' demand for a counterparty, cause the futures curve to become uninformative or even a misleading indicator of underlying demand and supply conditions. I therefore reject Sanders et al.'s (2010) verdict and conclude that index traders can indeed become "too much of a good thing."

The remainder of the paper is structured as following. In Section 2, I discuss the theories of intertemporal pricing and the hypothesized factors that drive the shape of the futures curve. In Section 3, I present a method for extracting factors that parsimoniously capture the dynamics of the futures curve. In Section 4, I outline the statistical methods and data used in the empirical analysis. The results are presented in Section 5 and I conclude in Section 6. 


\section{Commodity term structure models}

Futures curve models are commonly based on intertemporal pricing theories, such as theories of storage and theories of risk premium. Theories of storage or convenience yield are derived from a simple no-arbitrage condition between spot and futures prices, as summarized in equation (1):

$$
F_{t}^{T}=S_{t} e^{\left(r_{t}+w_{t}-y_{t}\right) \tau}
$$

where $F_{t}^{T}$ is the futures price at time $t$ with maturity date $T, S_{t}$ is the spot price at $t, r_{t}$ and $w_{t}$ are continuously compounded risk-free interest rate and storage costs, respectively, over time $\tau=T-$ $t$, and $y_{t}$ is the convenience yield. The latter is a utility-based reward that accrues to the holder of inventories. At maturity, $\tau \rightarrow 0$ so that $F_{T}^{T}=S_{T}$ and the market basis $B_{t} \equiv S_{t}-F_{t}^{T}$ is zero, implying convergence. A complementary pricing theory is the risk premium or hedging pressure approach, according to which the futures price is a biased predictor of the expected spot price so that:

$$
F_{t}^{T}=E_{t}\left[S_{T}\right] e^{-\rho_{t} \tau},
$$

with $\rho_{t}$ being the risk premium. The bias arises due to an insurance premium demanded by speculators who provide a risk management service to hedgers.

Hypothetically, there is a futures price $F_{t}^{T_{i}}$ for each maturity date $T_{i}$ with $T_{i}=t+i, i \in \mathbb{N}$. The combination of all futures price series with maturity dates $T_{i}$ is referred to as the term structure, while a set of prices at time $t$ is referred to as the futures curve (Borovkova, 2010). However, the futures curve cannot be observed fully as the set of simultaneously traded contracts is finite. If the futures curve is linear, the curve could be approximated by the spot rate plus the gradient estimated 
as the difference between two consecutive futures contracts. Taking the logs of equations (1) and (2), the gradient is approximated by:

$$
\begin{aligned}
& \frac{f_{t}^{T_{j}}-f_{t}^{T_{i}}}{\tau_{i j}}=r_{t}+w_{t}-y_{t} \\
& \frac{f_{t}^{T_{j}}-f_{t}^{T_{i}}}{\tau_{i j}}=\frac{1}{\tau_{i j}} E_{t}\left[\Delta s_{\tau_{i j}}\right]-\rho_{t},
\end{aligned}
$$

where $\tau_{i j}=T_{j}-T_{i}$, with $i<j$. In other words, the gradient is the calendar spread $\left(s_{\tau, t}\right)$ adjusted for differences in maturity dates. However, the imposition of linearity is too restrictive, as the convenience yield and risk premium might not evolve linearly over the futures curve. Indeed, nonliner shapes such as peaked slopes have been identified as common features (Litterman and Scheinkman, 1991). The calendar spread hence falls short of adequately capturing the dynamics of the futures curve.

While carry costs $\left(r_{t}+w_{t}\right)$ are observed, the convenience yield, price expectations, and risk premia in equation (3) are latent constructs. The convenience yield is commonly conceptualized as an inverse and non-linear function of inventory (Pindyck, 2001; Bozic und Fortenbery, 2011; Pirrong, 2011). The risk premium found more varied and potentially complementary interpretations in the literature; see Lautier (2005) for an overview. Broadly, two sets of theories have emerged: (1) theories of asset-pricing, which assign a risk premium to (systematic) risk (Kaldor, 1939; Dusak, 1973) and (2) theories of hedging pressure, which incorporate market imperfections into multi-period pricing models (Bessembinder, 1992; Chang, 1985; Hirshleifer, 1988, 1990). 
Hedging pressure theories have recently been complemented by a literature identifying a potentially offsetting price pressure effect by institutional investors who invest in broad-based commodity indices for portfolio diversification (e.g., Brunetti and Reiffen, 2014; Hamilton and Wu, 2014; Basak and Pavlova, 2016). These authors show that the risk premium, under the assumption of market frictions, is driven by both hedging and index pressure. As for hedging pressure models in general, the assumption of market frictions such as transaction costs ensures a finite elasticity of supply of speculative funds and hence demand-driven price effects. Brunetti and Reiffen (2014) derive a two-period equilibrium pricing model in which hedgers and speculators maximize their utility over consecutive trading cycles. Two implications follow immediately from their model; see Appendix A1 for a technical summary.

- Implication 1: Hedging and index pressure are offsetting forces so that hedging pressure is defined as short hedging positions net of index positions and index pressure is defined as long index positions net of hedging positions.

- Implication 2: The shape of the futures curve depends on the relative weight of index and hedging pressure in individual contracts.

Brunetti and Reiffen (2014) formulate and test their model with respect to the spread between two consecutively traded contracts but not the futures curve. By use of non-publicly available data, they show graphically that index positions are mostly located in the medium-term maturities. Extending these insights to the futures curve, index pressure is likely to cause non-linearity due to peaks in the contracts they are most active in. Index traders should hence contribute to a positive slope overall with an inverted U-shape, peaking at medium-term maturities. Hedging positions 
should have the reverse effect. A method that unveils the latent futures curve to formally test these hypotheses is outlined below. ${ }^{1}$

\section{Factor decomposition}

Principal component analysis (PCA) has been used as a data reduction technique to decompose the variation of future curves, foremost yield curves (e.g., Barber and Copper, 2012). However, PCA decomposition suffers from weight inconstancy and, resulting from its nonparametric nature, interpretability of the extracted components is difficult as no structure is imposed that could be linked to theory. Factor decomposition methods, such as suggested by Nelson and Siegel (1987), adjust for this shortcoming by presupposing structure.

The Nelson and Siegel (1987) decomposition rests on a set of differential equations that capture the dynamic components of the yield curve and thereby generate the typical shapes of the curve at any point in time. Diebold and Li (2006) show that by altering the original decomposition, the three extracted factors can be interpreted as level, slope, and curvature in a similar manner as suggested by Litterman and Scheinman (1991), who were the first to assign meaning to yield curve components extracted by PCA.

The model by Diebold and Li (2006) takes the following form with level, slope, and curvature $\{L, S, C\}$ jointly describing the futures curve:

$$
f_{t}(\tau)=\beta_{t, L} L+\beta_{t, S} S(\tau)+\beta_{t, C} C(\tau)+\vartheta_{t}(\tau),
$$

where $f_{t}(\tau)$ is the price of the commodity futures at time $t$ with time to maturity $\tau$. The factor scores $\beta_{t, j}, j \in\{L, S, C\}$ can be extracted by first calculating the factor loadings for the slope

\footnotetext{
${ }^{1}$ Brunetti and Reiffen (2014) partly compensate for the shortcoming that spreads cannot capture non-linearities by use of non-publicly available data that provides information about the specific contracts in which traders are active.
} 
$S(\tau)=\left(1-e^{-\lambda \tau} / \lambda \tau\right)$, the curvature $C(\tau)=S(\tau)-e^{-\lambda \tau}$, and the level $L=1$ for all $\tau$, for each contract's maturity at each point in time and second using ordinary least squares (OLS) to estimate $\beta_{t, j}$ at each $t$. It is easy to see that $f_{t}(\infty)=\beta_{t, L}, f_{t}(\infty)-f_{t}(0)=\beta_{t, S}$ and $\max C(\tau)=\lambda$. Therefore, the level factor has been termed the long run factor, while the slope factor is interpreted as the short run factor. The curvature is the medium run factor with $\lambda$ governing at which month $C(\tau)$ has a global maximum (see Figure 1).

[Figure 1 about here]

Following Karstanje et al. (2017), I add a trigometric function. The addition is motivated by suspected seasonality in the data and the observation of a fourth wave-shaped component in the PCA decomposition for coffee, cocoa, and cotton (see Appendix Figure A1). The additional factor takes the following form: $W(\tau)=\sin (\pi \lambda \tau){ }^{2}$ The functional form is simpler than in Karstanje et al. (2017) and offers a very good fit for the futures curves analyzed:

$$
f_{t}(\tau)=\beta_{t, L} L+\beta_{t, S} S(\tau)+\beta_{t, C} C(\tau)+\beta_{t, W} W(\tau)+\vartheta_{t}(\tau)
$$

While the shapes of the loadings are determined ex ante, the rate of decay $\lambda$ can be flexible. Hansen and Lunde (2013) find that allowing the decay factor to change over time does not improve model fit, while Baruník and Malinská (2016) find that a time-varying decay factor results in forecasting deterioration. Hence, I fix the decay factor, whereby the value of $\lambda$ is found by grid search so that the best fit is reached. I further follow Karstanje et al. (2017) in re-centring ${ }^{3}$ the loadings of the components for a clearer separation of the variation. The transformation is

${ }^{2}$ Inspired by Gilbert et al. (2017), I experimented with the addition of a phase parameter $\omega$ in $W(\tau)=\sin ((\lambda \tau+$ $\omega) \pi$ ) that shifts with the trading months, as seasonal patterns should depend on the months of year and not duration to maturity $\tau$. However, the addition did not improve overall fit.

${ }^{3}$ Re-centring is achieved by $S^{\prime}(\tau)=S(\tau)-S(1), C^{\prime}(\tau)=C(\tau)-C(1)$ and $W^{\prime}(\tau)=W(\tau)-W(1)$. 
motivated by the observation that the slope and the curvature factor can become almost indistinguishable if the futures curve is relatively flat.

Given the predetermined shapes of the factors, the obtained loadings are interpretable. The level reflects the overall price trend common across simultaneously traded contracts, while the slope indicates whether the market is normal or inverted. A positive factor value indicates a downward-sloping futures curve, i.e., the contracts with longer maturities trade at a discount (inverted), and a negative value indicates an upward sloping futures curve, i.e., contracts with shorter maturity trade at a discount (normal). A positive value for the curvature coefficient indicates a convex curve while a negative indicates a concave curve. A positive value for the wave component signals an $\mathrm{N}$-shaped futures curve and a negative value signals an inverted $\mathrm{N}$-shaped curve.

Recalling the conclusions reached in Section 2, the following testable relations are expected: hypotheses $\mathrm{H}(1)$ to $\mathrm{H}(3)$ :

$\mathrm{H}(1)$ : Index pressure to be associated with:

a. A normal market, i.e., an upward sloping futures curve.

b. A concave futures curve, i.e., a peaked curve.

c. Potential wave shapes due to roll-effects.

$H(2)$ : Hedging pressure to be associated with:

a, An inverted market, i.e., a downward sloping futures curve.

b. A convex futures curve, i.e., a U-shaped futures curve.

$\mathrm{H}(3)$ : Inventory to be associated with

a. An inverted market through the convenience yield.

b. Wave shapes, capturing seasonal cycles. 
These hypotheses resonate with findings presented in the empirical literature. Etienne and Mattos (2016) apply the Nelson-Siegel factor decomposition to empirically test theories of storage and convenience yield and find support for (H3a). Karstanje et al. (2017) test the excessive comovement hypothesis, also linked to financialization, on the extracted factors. Heidorn et al. (2015), like this study, link the extracted factors to trader positions in the oil market and find that index positions influence the slope and curvature factors but not the level in support of (H1a-b). Their finding aligns with the previously made argument that price levels are predominantly driven by demand and supply fundamentals as well as noise.

\section{Method and data}

The empirical analysis is conducted in three stages: (1) hypothesis testing based on a simple spread analysis ignoring non-linearity; (2) factor decomposition; and (3) hypothesis testing based on factor decomposition. I chose an unrestricted error correction model (ECM) specification for stages (i) and (iii). The model choice is motivated by the observation that extracted slope and curvature factors are trended. Unrestricted ECMs are robust in the presence of dominant trends and are flexible as they incorporate both levels and differences, thereby incorporating potential long run relations, as follows:

$$
\Delta y_{t}=\alpha_{0}+\alpha(L) \Delta y_{t-1}+\Omega(L) \Delta Z_{t}+\phi\left[y-\gamma^{\prime} Z\right]_{t-1}+u_{t}
$$

$Z_{t}=\left[r_{t}, \psi_{t}, \psi_{t}^{2}, \rho_{H, t}, \rho_{I, t}\right]^{\prime}$ is the set of explanatory variables informed by the two theoretical strands outlined in equation (3), where storage costs and convenience yield are modeled as nonlinear functions of inventory $\psi_{t}$. Following, implication 1 derived from the model proposed by Brunetti and Reiffen (2014), the risk premium is modeled as a function of hedging pressure $\rho_{H, t}$ and index pressure $\rho_{I, t} . \Omega$ is a coefficient matrix and $\gamma^{\prime}$ is the cointegrating vector, which can be 
recovered if $\phi$ is significant. The set of dependent variables is given by $y_{t}=\left\{s_{t}, \beta_{j, t}\right\}$, with $j=$ $\{S, C, W\}$ from equations (3) and (5). I do not consider the level factor in the analysis for the previously mentioned reason and the derived hypotheses $\mathrm{H}(1)$ to $\mathrm{H}(3)$ are formulated with respect to extracted slope, curvature, and wave factors only. The appropriate lag length of equation (6) is found by general-to-specific modeling (Campos et al., 2005). ${ }^{4}$

As elaborated in Section 2, hedging and index pressure are offsetting forces. Index traders are liquidity providers if hedging pressure prevails and are liquidity consumers otherwise. Hence, I create indicators that capture this net effect. The Commodity Futures Trading Commission (CFTC) provides a breakdown of each Tuesday's open interest by different trader types for U.S. futures exchanges in three weekly flagship reports. Among these reports, the Commodity Index Trader Supplement (CIT), despite its shortcomings, ${ }^{5}$ was found to reflect index positions most accurately and, therefore, is chosen for this study (Irwin and Sanders, 2012). The CIT reports provide open interest $(O I)$ disaggregated by long and short positions and trader type including noncommercial traders, commercial traders (com), index traders (ind), and small non-reporting traders.

I define hedging pressure as the commercial net long positions (short hedging positions after internal netting) that are not covered by index net long positions (long positions after internal netting) as a share of total open interest and vice versa for index pressure. ${ }^{6}$ In other words, the

\footnotetext{
${ }^{4}$ The GETS package provided by OxMetrics has been used starting from a general unrestricted model with 12 lags.

${ }^{5}$ See CFTC (2006), Sanders et al. (2010), and Irwin and Sanders (2011) for a discussion.

${ }^{6}$ This definition assumes that commercial hedgers are predominantly short and index traders predominantly long in the market. While this assumption holds over the period analysed here, it is possible that net-long commercial positions turn positive. In these rare instances, the index pressure indicator would capture some long hedging positions as well. As it is unlikely that positive net-long hedging positions prevail or are particularly large, I still refer to $\rho_{I, t}$ as index pressure.
} 
indicators provide a measure of the excess in long or short positions after internally netting index and commercial hedger positions as a percentage of open interest:

$$
\begin{gathered}
\rho_{H, t}= \begin{cases}\frac{\left|\operatorname{com}_{n l}+i n d_{n l}\right|}{O I_{\text {total }}} & \text { if } \operatorname{com}_{n l}+i n d_{n l}<0 \\
0 & \text { if } \operatorname{com}_{n l}+i n d_{n l} \geq 0\end{cases} \\
\rho_{I, t}= \begin{cases}\frac{\left|\operatorname{com}_{n l}+i n d_{n l}\right|}{O I_{\text {total }}} & \text { if } \operatorname{com}_{n l}+i n d_{n l}>0 \\
0 & \text { if } \operatorname{com}_{n l}+i n d_{n l} \leq 0 .\end{cases}
\end{gathered}
$$

Index pressure is most pronounced in the coffee market and almost absent in the cotton market where short hedging positions outweigh long index positions most of the time (Figure 2). The average index pressure effect is hence expected to be negligible for cotton but significant for coffee.

[Figure 2 about here]

CIT data are available weekly from 2006, while inventory data are only available in monthly frequency. Hence, equation (6) is estimated using monthly data from January 2006:M1 to 2017:M6. The first twelve months 2006:M1-2006:M12 are used to evaluate appropriate lag structure. Price data for the different futures contracts and the "risk-free" interest rate, approximated by the 3-month Libor rate, are obtained from Thomson Reuters Datastream. Only the first 8 simultaneously traded contracts are used for the factor construction in equation (5) due to concerns over low liquidity in the more deferred contracts. Inventory data for the cocoa and coffee commodities are obtained from the CME Registry. Data for the cotton inventory are from the U.S. Department of Agriculture (USDA). 


\section{Results}

For the first stage of the analysis, I use the calendar spread between the contracts with the $7^{\text {th }}$ and $2^{\text {nd }}$ nearest maturity dates (7-2 spread) to estimate equation (6). Prices are in logarithms following equation (3). At maturity of the nearest to maturity contract, the series are rolled over. Cocoa, coffee, and cotton contracts are traded for 5 maturity months: March, May, July, September (October for cotton), and December. The 7-2 spread is hence the difference between two contracts maturing in the same calendar months, which should minimize seasonality. The 6-1 spread was not considered to avoid volatility close to maturity. Other spreads were experimented with, but the results did not change, which is unsurprising given their similarity (see Appendix Figure A2). Estimation results are reported in Table 1.

[Table 1 about here]

Both index and hedging pressure coefficients are highly significant across markets, except for index pressure in cotton. As expected following $\mathrm{H}(1 \mathrm{a})$ and $\mathrm{H}(2 \mathrm{a})$, index pressure is associated with an increase in the spread while hedging pressure is associated with a decrease in the spread, and index pressure is smallest for cotton and largest for coffee. For instance, a $1 \%$ increase in index pressure is estimated to result in a $0.25 \%$ increase in the coffee $7-2$ spread. The effect is slightly larger for hedging pressure. Only for cocoa is a significant long run relation found, where a $1 \%$ increase in index pressure results in a $0.93 \%$ increase in the cocoa $7-2$ spread in the long run. With a speed of adjustment coefficient of 0.23 , the spread adjusts to $50 \%$ of the full effect in roughly 3 months, which is a $0.23 \%$ increase in the cocoa spread in the first months, a slightly smaller effect than found for coffee. Results also support the convenience yield hypothesis with inventory being significant for all markets in line with $\mathrm{H}(3 \mathrm{a})$. The signs of the coefficients are not easily interpretable because of their polynomial nature. 
As mentioned above, calendar spreads are unable to capture non-linear shapes of futures curves. This recognition motivates the suggested factor decomposition. Figure 3 depicts the extracted factor scores from equation (5) with the corresponding autocorrelation functions. The slope factors exhibit the slowest dynamics with the most inertia, while the wave factors exhibit the fastest dynamics with seasonal patterns following harvest cycles; annual for coffee and cocoa and bi-annual for cotton due to the more geographically disperse production.

[Figure 3 about here]

On average, the factor decomposition of equation (5) captures $90 \%$ to $99 \%$ of total variation (Appendix Table A1). The wave factor only marginally contributes to the average R-squares of equation (5) but remarkably improves the fit of the futures curves in instances of multiple extrema, which is a problem identified by Diebold and Li (2006) for their decomposition. The maximum for the curvature factor, coinciding with the turning point of the wave factor, lies between the $7^{\text {th }}$ and the $9^{\text {th }}$ month, which is the end of the first third of the observed futures curve.

In the final stage of the analysis, I use the extracted factors to estimate equation (6). Results are reported in Table 2. As in the spread analysis, results support both the index and hedging pressure hypothesis. Index pressure is associated with an upward-sloping futures curve, while hedging pressure has the offsetting effect, in line with $\mathrm{H}(1 \mathrm{a})$ and $\mathrm{H}(2 \mathrm{a})$. The average index pressure effect is strongest for coffee and weakest (and again insignificant) for cotton. For coffee, index pressure is also associated with a concave futures curve, while hedging pressure is strongly associated with a convex futures curve for all three soft commodities as predicted by $\mathrm{H}(1 \mathrm{~b})$ and $\mathrm{H}(2 \mathrm{~b})$. Further, index pressure is associated with N-shaped futures curves for coffee and cocoa, explained by roll effects, with the price of the maturing contract declining with the exit of index traders and the price of the deferred medium-term contract increasing with the entry of index 
traders, in line with H(1c). This observation corroborates Mou's (2011) finding of predictable and exploitable roll effects.

[Table 2 about here]

Table 2 also provides evidence for the convenience yield hypothesis for cocoa and cotton, including a non-linear relation between convenience yield and level of storage. Inventory variables are leading the slope factor in line with $\mathrm{H}(3 \mathrm{a})$. A strong effect of levels of inventory is also found for the wave factor for all three commodity markets, supporting the argument that the wave component captures, at least partially, seasonal variations as suggested by $\mathrm{H}(3 \mathrm{~b})$. While the size of coefficient estimates is not directly interpretable due to the way the extracted factors are constructed, they are comparable across markets regarding the relative strength of the effect. Overall, the index pressure effects are strongest for the coffee and cocoa term structure, while hedging pressure has the strongest effect on the cotton term structure. Inventory is least important for the coffee term structure, suggesting that the market has a larger share of speculative noise compared to the other two markets.

In most instances, index and hedging pressure variables enter with contemporaneous terms. This is expected given the immediate pass-through of changes in trader positions to changes in prices. However, this implies that coefficient estimates presented in Table 2 potentially suffer from endogeneity bias. Gilbert and Pfuderer (2014) suggest an instrumental variable (IV) treatment for CIT positions with VIX based on S\&P 500 and Dow Jones Commodity Index total returns as instruments. To test for the robustness of the results in Table 2, I replicate their IV estimation. Results are summarized in the Appendix Table A2, with only the instrumentalized index and hedging pressure coefficients reported for brevity. As in Gilbert and Pfuderer (2014) instruments are valid and index pressure coefficients are significantly larger (in absolute terms) than reported 
in Table 2. Hedging pressure coefficients are unchanged or insignificant. As hedging positions are unlikely to be correlated with the suggested financial instruments, I extend the original set of instruments by lagged inventory variables with hedging pressure coefficients being now closer to results in Table 2. Overall, the findings reported in Table 2 are confirmed and index pressure effects obtained by OLS tend to have a slight downward bias if any at all.

\section{Conclusion}

Based on the two-period equilibrium pricing model proposed by Brunetti and Reiffen (2014), I hypothesize that hedging and index positions have inverse and offsetting effects on the shape of commodity futures curves. I refer to these effects as hedging pressure and index pressure.

By use of factor decomposition, I show that index traders act as liquidity providers for the three soft commodity markets analyzed and hence have a dampening effect on hedging pressure, thereby reducing hedging costs as predicted by Brunetti and Reiffen (2014) and others. However, when index long positions exceed short hedging demand, index traders' positions do not only offset hedging pressure effects but cause an upward-sloping and peaked futures curve with occasional wave-like shapes linked to roll effects. These effects are clearly identified through factor decomposition.

While these index pressure effects appear moderate for cotton, the cocoa and coffee term structures are more strongly affected, with potentially adverse consequences for the informativeness of futures curves. I thus argue that index traders' positions can turn into "too much of a good thing." While index traders are welcomed liquidity providers, their presence distorts price discover mechanisms if they become liquidity consumers rather than providers. This is a relevant concern not only for the soft commodity markets analyzed, but other commodity markets 
that have seen an even larger inflow of index investment over the last decade, such as grains, energy, and metals. 


\section{References}

Barber, Joel R., and Mark L. Copper. 2012. "Principal Component Analysis of Yield Curve Movements." Journal of Economics and Finance, 36 750-765.

Baruník, Jozef, and Barbor Malinská. 2016. "Forecasting the term structure of crude oil futures prices with neural networks.” Applied Energy, 164 366-379.

Basak, Suleyman, and Anna Pavlova. 2016. "A Model of Financialization of Commodities." The Journal of Finance, 71(4) 1511-1556.

Bessembinder, Hendrik. 1992. "Systematic Risk, Hedging Pressure, and Risk Premiums in Futures Markets." The Review of Financial Studies, 5 (4) 637-667.

Borovkova, Svetlana. 2010. "Detecting Market Transitions and Energy Futures Risk Management Using Principal Components.” The European Journal of Finance, 12(6-7) 495-512.

Bozic, Marin, and T. Randall Fortenbery. 2011. "Pricing Options on Commodity Futures: The Role of Weather and Storage." Selected Paper prepared for presentation at the Agricultural \& Applied Economics Association's 2011 AAEA \& NAREA Joint Annual Meeting, Pittsburgh, Pennsylvania, July 24-26, 2011.

Brunetti, Celso, and David Reiffen. 2014. "Commodity Index Trading and Hedging Costs." Journal of Financial Markets, 21 (Federal Reserve Board) 153-180.

Campos, Julia, Neil R. Ericsson, and David F. Hendry. 2005. "General-to-specific Modeling: An Overview and Selected Bibliography." Board of Governors of the Federal Reserve System International Finance Discussion Papers, No. 838.

CFTC. 2006. Comprehensive Review of the Commitments of Traders Reporting. Washington, DC: Commodity Futures Trading Commission.

Chang, Eric C. 1985. "Returns to Speculators and the Theory of Normal Backwardatio." The Journal of Finance, 40 (1) 193-208.

Cheng, Ing-Haw, and Wei Xiong. 2014. "The Financialization of Commodity Markets.” Annual Review of Financial Economics, 6 419-441.

Diebold, Francis X., and Canlin Li. 2006. "Forecasting the Term Structure of Government Bond Yields." Journal of Econometrics, 130 337-364. 
Dusak, Katherine. 1973. "Futures Trading and Investor Returns: An Investigation of Commodity Market Risk Premiums.” Journal of Political Economy, 81 (6) 1387-1406.

Etienne, Xiaoli L., and Fabio Mattos. 2016. "The Information Content in the Term Structure of Commodity Prices." Proceedings of the NCCC-134 Conference on Applied Commodity Price Analysis, Forecasting, and Market Risk Management. St. Louis, MO.

Fattouh, Bassam, Lutz Kilian, and Lavan Mahadeva. 2013. "The Role of Speculation in Oil Markets: What Have We Learned So Far?” Energy Journal, 34 7-33.

Gilbert, Christopher L., and Simone Pfuderer. 2014. "The Role of Index Trading in Price Formation in the Grains and Oilseeds Markets." Journal of Agricultural Economics, 65 (2) 303-322.

Gilbert, Christopher L., Luc Christiaensen, and Jonathan Kaminski. 2017. "Food price seasonality in Africa: Measurement and extent." Food Policy, 67 119-132.

Hamilton, James D., and Jing Cynthia Wu. 2014. "Risk Premia in Crude Oil Futures Prices." Journal of International Money and Finance, 42 9-37.

Hansen, Niels S., and Asger Lunde. 2013. "Analyzing Oil Futures with a Dynamic Nelson-Siegel Model.” CREATES Research Papers 2013-36, Department of Economics and Business Economics, Aarhus University.

Heidorn, Thomas, Frieder Mokinski, Christoph Rühl, and Christian Schmaltz. 2015. "The impact of fundamental and financial traders on the term structure of oil.” Energy Economics, 48 276-287.

Hirshleifer, David. 1990. "Hedging Pressure and Futures Price Movements in a General Equilibrium Model.” Econometrica, 58 (2) 411-428.

Hirshleifer, David. 1988. "Residual Risk, Trading Costs, and Commodity Futures Risk Premia." The Review of Financial Studies, 1 (2) 173-193.

Irwin, Scott H. 2013. "Commodity Index Investment and Food Prices: Does the "Masters Hypothesis" Explain Recent Price Spikes?” Agricultural Economics, 44 (supplement) 2941. 
Irwin, Scott H., and Dwight R. Sanders. 2011. "Index Funds, Financialization, and Commodity Futures Markets.” Applied Economic Perspectives and Policy, 33 (1) 1-31.

Irwin, Scott H., and Dwight R. Sanders. 2012. "Testing the Masters Hypothesis in commodity futures markets.” Energy Economics, 34(1) 256-269.

Irwin, Scott H., P. Garcia, D. L. Good, and E. L. Kunda. 2011. "Spread and Non-Convergence in Chicago Board of Trade Corn, Soybeans, and Wheat Futures: Are Index Funds to Blame." Applied Economics Perspective and Policy, 33 (1) 116-142.

Kaldor, Nicholas. 1939. "Speculation and Economic Stability.” The Review of Economic Studies, 7 (1) 1-27.

Karstanje, Dennis, Michel van der Wel, and Dick J. C. van Dijk. 2017. "Common Factors in Commodity Futures Curves.” http://dx.doi.org/10.2139/ssrn.2558014.

Lautier, Delphine. 2005. "Term Structure Models of Commodity Prices: A Review." Journal of Alternative Investments, 8 (1) 42-64.

Litterman, Robert, and José Scheinkman. 1991. "Common Factors Affecting Bond Returns.” The Journal of Fixed Income 54-61.

Masters, Michael W. 2008. "Testimony of Michael W. Masters before the Committee on Homeland Security and Governmental Affairs United States Senate, May 20, 2008.”

Mou, Yiqun. 2011. "Limits to Arbitrage and Commodity Index Investment: Front-Running the Goldman Roll.” Columbia Business School: Working Paper.

Nelson, Charles R., and Andrew F. Siegel. 1987. "Parsimonious Modeling of Yield Curves." The Journal of Business, 60(4) 473-489.

Pindyck, Robert S. 2001. "The Dynamics of Commodity Spot and Futures Markets: A Primer." The Energy Journal, 22 (3) 1-29.

Pirrong, Craig. 2011. "Stochastic Fundamental Volatility, Speculation, and Commodity Storage." In Commodity Price Dynamics: A Structural Approach, by Craig Pirrong, 109-130. Cambridge, UK: Cambridge University Press. 
Sanders, Dwight R., Scott H. Irwin, and Robert P. Merrin. 2010. "The Adequacy of Speculation in Agricultural Futures Markets: Too Much of a Good Thing?" Applied Economic Perspectives and Policy, 32 (1) 77-94.

US Senate. 2009. Excessive Speculation in the Wheat Market: United States Senate: Washington D.C.: United States Senate Permanent Subcommittee on Investigations.

Van Huellen, Sophie. 2018. "How financial investment distorts food prices: evidence from U.S. grain markets." Agricultural Economics, 49 171-181.

\section{Acknowledgment}

The research was supported financially by the German National Academic Foundation and

Andrey Kuleshov and Elena Ivashentseva. This article greatly benefitted from comments by Machiko Nissanke, Raphael Kaplinsky, and Joerg Mayer. 


\section{Appendix}

\section{A1. Technical summary of the two-period model by Brunetti and Reiffen (2014)}

I assume that hedgers and speculators invest in futures contracts that mature in periods one and two respectively. Their utility functions only differ in cash market positions, or inventory $(\psi)$, that are realised by hedgers after the last trading cycle. Index traders' positions $(I)$ are assumed exogeneous. The utility function of hedgers and speculators is given by:

$$
U\left[W_{0}+X_{1}^{2} \Delta F_{1}^{2}+X_{2}^{2} \Delta F_{2}^{2}+X_{1}^{1} \Delta F_{1}^{1}+F_{2}^{2} \psi_{k}\right]
$$

with $W_{0}$ being initial wealth, $X_{t}^{T}$ being the trader's position at time $t=\{0,1,2\}$ in the futures contract that matures at time $T=\{1,2\}$ and $\Delta F_{t}^{T}=F_{t}^{T}-F_{t-1}^{T}$ being the respective price changes of the futures contracts. $\psi_{k}=\{0, \psi\}$ for speculators and hedgers respectively. Each trader maximises utility with respect to total wealth consumed in $t=2, W_{2}$.

A standard exponential utility function is assumed for traders and speculators alike with normally distributed price changes, so that traders' utility functions depend solely on the mean and variancecovariance of price changes:

$$
U(W)=A-\mathrm{e}^{\left(-\alpha W_{2}\right)}
$$

Market clearing conditions in both futures contracts $T=\{1,2\}$ with index trader positions are specified as:

$$
\begin{aligned}
& X_{1}^{1}\left(N_{H}+N_{S}\right)=-\gamma I_{1} \\
& X_{1}^{2}\left(N_{H}+N_{S}\right)=N_{H} \psi-(1-\gamma) I_{1},
\end{aligned}
$$

where $N_{H}, N_{S}$ is the number of hedgers and speculators respectively. $I_{1}$ is total index positions at $t=0$ invested in both the near-by and deferred maturity contract and $\gamma$ is the percentage share 
invested in the nearby contract $T=1 . X_{1, H}^{1}=X_{1, S}^{1}$ following from (A1) as $\psi_{k}$ becomes binding only in the deferred futures contract and therefore $X_{1, H}^{2}+\psi=X_{1, S}^{2}$.

When solving for $F_{0}^{1}$ and $F_{0}^{2}$ by use of backward induction, the spread between the two consecutive futures contracts can be derived as $S_{0} \equiv F_{0}^{2}-F_{0}^{1}$, in line with (3b) with $\tau_{i j}=1, t=0$ and $T=$ $\{2,1\}$, with risk premium:

$\rho_{o}=\frac{\alpha}{N_{H}+N_{S}}\left[I_{1}\left[\left(\sigma_{1}^{12}-\left(\sigma_{1}^{1}\right)^{2}\right)(\gamma)+\left(\left(\sigma_{1}^{2}\right)^{2}-\sigma_{1}^{12}\right)(1-\gamma)\right]+I_{2} R\left[\sigma_{12}^{2}+\sigma_{12}^{12}-\left(\sigma_{1}^{2}\right)^{2}-\sigma_{1}^{12}\right]+\right.$ $\left.\psi\left[\left(\left(\sigma_{1}^{2}\right)^{2}-\sigma_{1}^{12}\right)\left(N_{S}\right)-\left(\sigma_{12}^{2}+\sigma_{12}^{12}\right)\left(N_{H} R\right)-\left(\left(\sigma_{1}^{2}\right)^{2}+\sigma_{1}^{12}\right)\left(N_{S} R\right)\right]\right]$,

where $R \equiv\left[N_{S}^{1} /\left(N_{H}^{1}+N_{S}^{1}\right)\right] /\left[N_{S}^{0} /\left(N_{H}^{0}+N_{S}^{0}\right)\right]$. It is easy to see that if $\psi=0$ and $I=0$, the spread is an unbiased estimator of future price changes, i.e., $S_{0}=E_{0}\left[\Delta S_{\tau_{12}}\right]$ with $\rho_{0}=0$. Further, without hedging demand, that is $\psi=0$, hedgers and speculators are identical (as in contract one) and the risk premium would only persist in the presence of index traders. From the definition of the risk premium in (A5), the following implications can be derived.

Implication 1: Hedging and index pressure are offsetting forces so that hedging pressure is defined as short hedging positions net of index positions and index pressure is defined as long index positions net of hedging positions.

As evident from the market clearing conditions specified in (A3) and (A4), both hedgers and speculators act as counterparty for index traders in (A3) and the demand for counterparty positions in (A4) depends on net-hedging demand, net of index trader positions. For example, if $N_{H} \psi=$ $(1-\gamma) I_{1}$ or $N_{S} \psi=-(1-\gamma) I_{1}$ and $\gamma=0$ so that $N_{H} \psi=I_{1}$ and $N_{S} \psi=-I_{1}$, which implies no 
hedging or index pressure in the $T=1$ contract and exactly offsetting positions by hedgers and index traders in the $T=2$ contract:

$$
\begin{gathered}
\rho_{o}=\frac{\alpha}{N_{H}+N_{S}}\left[\left(\sigma_{12}^{2}+\sigma_{12}^{12}\right)\left(I_{2}-I_{1}\right) R-\left(\left(\sigma_{2}^{1}\right)^{2}+\sigma_{1}^{12}\right)\left(I_{2}-I_{1}\right) R\right] \\
=\frac{\alpha \Delta I_{1} R}{N_{H}+N_{S}}\left[\sigma_{12}^{2}+\sigma_{12}^{12}-\left(\sigma_{2}^{1}\right)^{2}-\sigma_{1}^{12}\right]
\end{gathered}
$$

Therefore, if no new index traders enter at $t=1$ into the $T=2$ contract so that $I_{2}=I_{1}$, the risk premium is zero as hedging and index pressure cancel out.

Implication 2: The shape of the futures curve depends on the relative weight of index and hedging pressure in individual contracts.

This implication is evident from the comparative static analysis of (A5):

$$
\begin{aligned}
& \frac{\partial S_{0}}{\partial \gamma}=\frac{\alpha I_{1}}{N_{S}+N_{H}}\left[2 \sigma_{1}^{12}-\left(\sigma_{1}^{1}\right)^{2}-\left(\sigma_{1}^{2}\right)^{2}\right] \\
& \frac{\partial S_{0}}{\partial I_{1}}=\frac{\alpha}{N_{S}+N_{H}}\left[(2 \gamma-1) \sigma_{1}^{12}-\gamma\left(\sigma_{1}^{1}\right)^{2}+(1-\gamma)\left(\sigma_{1}^{2}\right)^{2}\right] .
\end{aligned}
$$

For instance, if $\gamma \downarrow$, that is index traders roll from contract $T=1$ to $T=2$, the spread increases. If $I \uparrow$ and $\gamma=1$, that is all index traders are in contract $T=1$, the spread decreases, and if $I \uparrow$ and $\gamma=0$, that is all index traders are in contract $T=2$, the spread increases. 

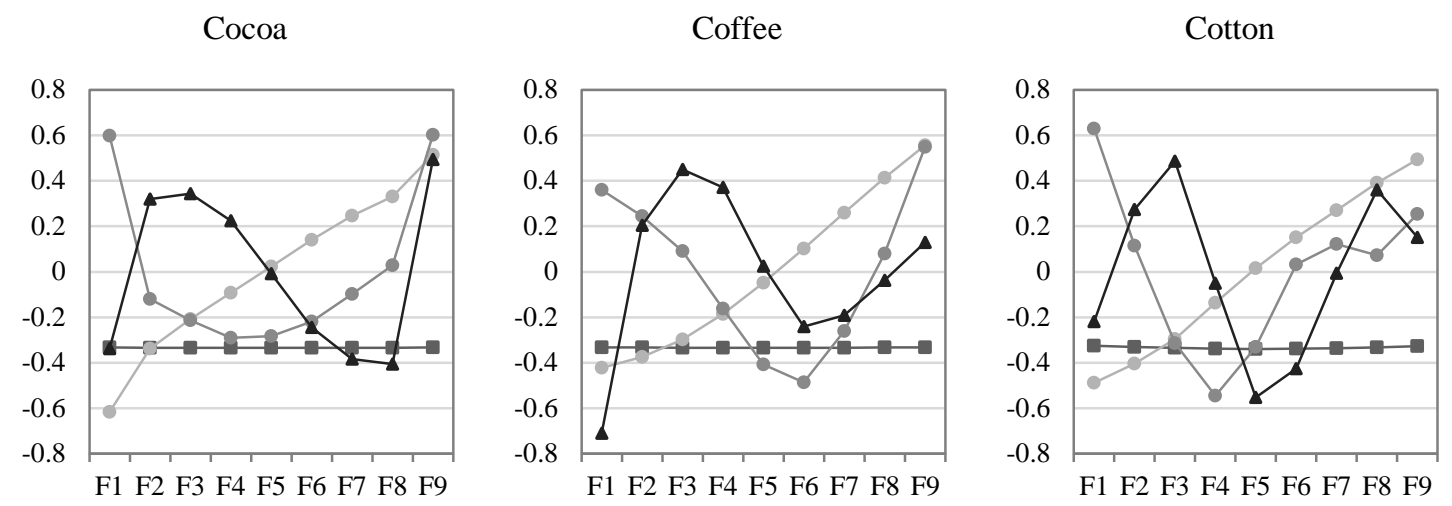

$\longrightarrow$ PC1 - Level

$\longrightarrow$ PC2 - Slope $\longrightarrow$ PC3 - Curvature

$\multimap$ PC4 - Wave

Figure A1. First four principal components

Note: Contracts have been logged and standardized. Monthly data 2006:M1-2017:M7. 

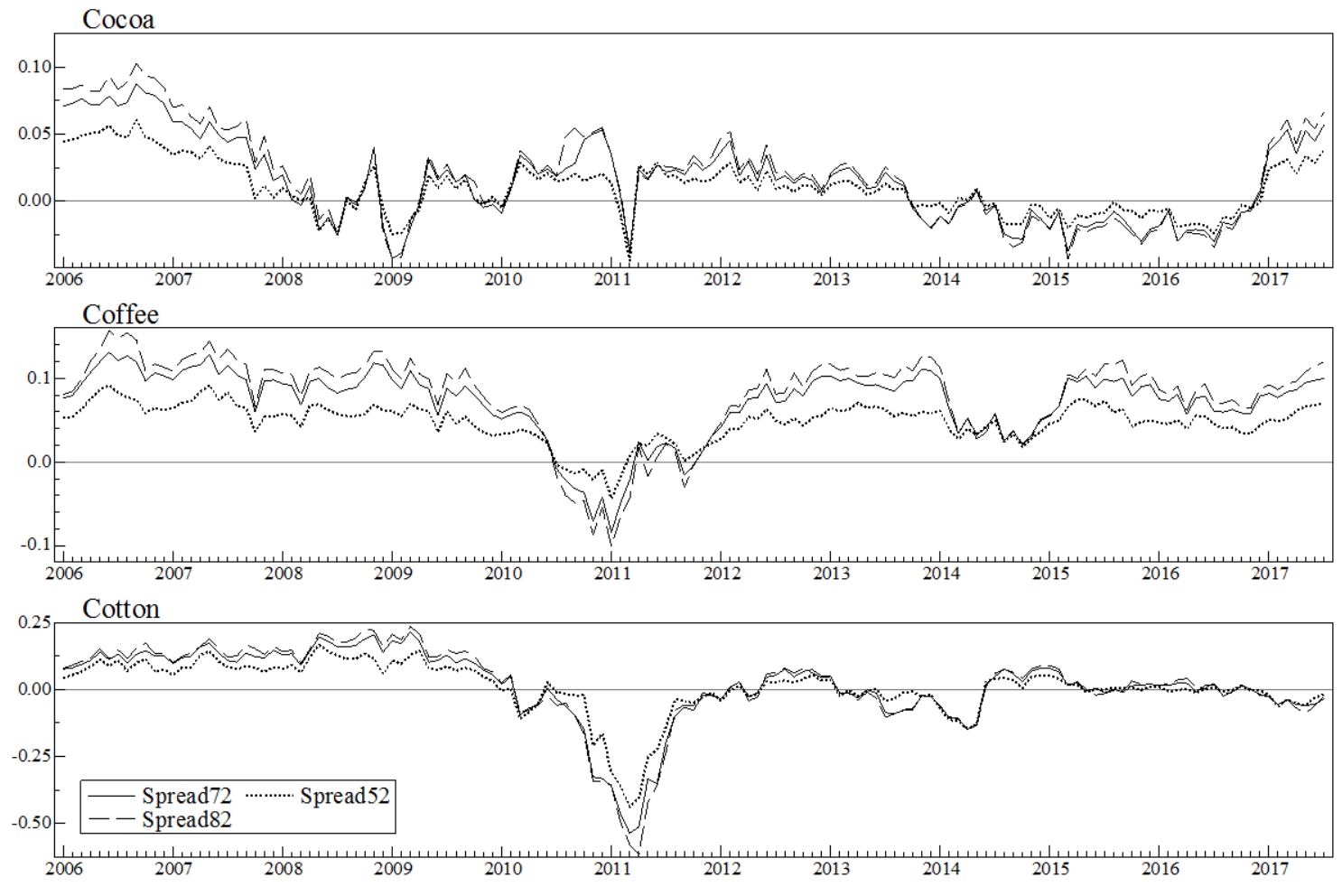

Figure A2. Cocoa, coffee, and cotton calendar spreads

Note: The 7-2 spread is constructed as the $7^{\text {th }}$ nearest to maturity contract less the $2^{\text {nd }}$ nearest to maturity contract, both in logarithms. At maturity of the nearest to maturity contract, series are rolled over. 
Table A1. Value of $\lambda$ and average $\mathrm{R}^{2}$ for equation (5)

\begin{tabular}{llcc} 
& $\tau$ & $\lambda$ & $\mathrm{R}^{2}$ \\
\hline Cocoa & 8 & 0.2242 & 0.9673 \\
Coffee & 9 & 0.1993 & 0.9943 \\
Cotton & 7 & 0.2562 & 0.9170 \\
\hline
\end{tabular}

Note: Values for $\tau$ and $\lambda$ with $\max C(\tau)=\lambda . \mathrm{R}^{2}$ is the average over 2006:M1-2017:M7. 
Table A2. Instrumental variable estimation of equation (6) with $y_{t}=\beta_{j, t}, j=\{S, C, W\}$

\begin{tabular}{|c|c|c|c|c|c|c|c|c|c|c|c|c|}
\hline & \multicolumn{2}{|c|}{ Slope } & \multicolumn{2}{|c|}{ Curvature } & \multicolumn{4}{|c|}{ Wave } & & \multirow{2}{*}{\multicolumn{3}{|c|}{$\begin{array}{c}\text { Sargan }(\mathrm{S}) \text { and } \\
\text { Wu-Hausman }(\mathrm{H}) \text { test }\end{array}$}} \\
\hline & \multirow{2}{*}{$\begin{array}{c}\rho_{I, t} \\
(L) \omega_{\rho_{I}}\end{array}$} & \multirow{2}{*}{$\begin{array}{c}\rho_{H, t} \\
(L) \omega_{\rho_{H}}\end{array}$} & \multirow{2}{*}{$\begin{array}{c}\rho_{I, t} \\
(L) \omega_{\rho_{I}}\end{array}$} & \multirow{2}{*}{$\begin{array}{c}\rho_{H, t} \\
(L) \omega_{\rho_{H}}\end{array}$} & \multirow{2}{*}{\multicolumn{2}{|c|}{$\begin{array}{c}\rho_{I, t} \\
(L) \omega_{\rho_{I}}\end{array}$}} & \multirow{2}{*}{\multicolumn{2}{|c|}{$\begin{array}{c}\rho_{H, t} \\
(L) \omega_{\rho_{H}}\end{array}$}} & & & & \\
\hline & & & & & & & & & & Slope & Curv. & Wave \\
\hline \multicolumn{13}{|c|}{ Indicator Set 1} \\
\hline \multirow[t]{2}{*}{ Cocoa } & $-1.3199 *$ & 0.0391 & 0.3543 & -0.0030 & 0.0108 & & $0.0164 *$ & & $\mathrm{~S}$ & 19.2 & 15.8 & 23.5 \\
\hline & $(0.538)$ & $(0.296)$ & (1.076) & $(0.592)$ & $(0.038)$ & & $(0.008)$ & & $\mathrm{H}$ & $57.7 * *$ & $66.8 * *$ & $80.2^{* *}$ \\
\hline \multirow[t]{2}{*}{ Coffee } & $-1.5713 * *$ & $0.7719 *$ & $-1.9327 *$ & 0.4462 & 0.0600 & & -0.0068 & & $\mathrm{~S}$ & 32.6 & 32.2 & 33.6 \\
\hline & $(0.453)$ & $(0.298)$ & $(0.865)$ & $(0.546)$ & $(0.033)$ & & $(0.020)$ & & $\mathrm{H}$ & $59.2 * *$ & $23.9 * *$ & $69.3 * *$ \\
\hline \multirow[t]{2}{*}{ Cotton } & 0.3630 & $0.9949 *$ & -2.6612 & 0.2720 & -0.0276 & & -0.0388 & & $\mathrm{~S}$ & 24.8 & 18.7 & - \\
\hline & $(0.933)$ & $(0.406)$ & $(2.135)$ & $(0.923)$ & $(0.062)$ & [3] & $(0.027)$ & [1] & $\mathrm{H}$ & $22.5^{* *} *$ & $14.6^{* * *}$ & - \\
\hline \multicolumn{13}{|c|}{ Indicator Set 2} \\
\hline \multirow[t]{2}{*}{ Cocoa } & $-1.0311 * *$ & 0.3805 & -0.4664 & $0.9530^{*}$ & 0.0213 & & $0.0168 *$ & & $\mathrm{~S}$ & 42.1 & 42.6 & $56.2^{*}$ \\
\hline & $(0.390)$ & $(0.196)$ & $(0.830)$ & $(0.457)$ & $(0.032)$ & & $(0.008)$ & [1] & $\mathrm{H}$ & $69.6^{* *}$ & $70.2 * *$ & $80.7 * *$ \\
\hline \multirow[t]{2}{*}{ Coffee } & $-1.1040 * *$ & $0.6270^{*}$ & $-1.7770 * *$ & 0.4779 & $0.0662 * *$ & & -0.0103 & & $\mathrm{~S}$ & 56.7 & 55.1 & 49.5 \\
\hline & $(0.356)$ & $(0.252)$ & $(0.645)$ & $(0.459)$ & $(0.024)$ & & $(0.017)$ & & $\mathrm{H}$ & $56.3^{* *}$ & $27.8 * *$ & $74.3^{* *}$ \\
\hline \multirow[t]{2}{*}{ Cotton } & 0.6509 & $1.0505^{* *}$ & 0.2176 & 1.4721 & -0.0276 & & -0.0388 & & $\mathrm{~S}$ & 46.9 & 62.9 & - \\
\hline & $(0.748)$ & $(0.341)$ & (1.633) & $(0.759)$ & $(0.062)$ & [3] & $(0.027)$ & [1] & $\mathrm{H}$ & $25.2 * *$ & $16.5 * *$ & - \\
\hline
\end{tabular}

Note: Coefficients of remaining variables are not reported here as they are not significantly different from Table 2. Estimation 2007:M12017:M7 - to allow enough room for appropriate lag selection. Standard errors in parentheses. Lag length selected in brackets. Variables that enter as lag are not instrumentalized. * significant at the $5 \%$ level; ** significant at the $1 \%$ level. (S) Sargan test for over-identification and (H) Wu-Hausman test of no endogeneity. Indicator Set 1: $\left\{(L) \Delta D J_{t-1},(L) \Delta V I X_{t-1},(L) D_{t-1}\right\}$. Indicator Set 2: $\left\{(L) D J_{t-1},(L) V I X_{t-1},(L) D_{t-1},(L) \Delta \psi_{t-1},(L) \Delta \psi_{t-1}^{2}\right\}$. DJ is the Dow-Jones Commodity Index (total returns), VIX is the volatility index based on S\&P500, D is a hedging pressure dummy taking on $\{1,0\}$. 


\section{Tables}

Table 1. Estimation of equation (6) with $y_{t}=s_{t}$

\begin{tabular}{|c|c|c|c|c|c|c|c|c|c|c|}
\hline & Constant & $y_{t}$ & $\psi_{t}$ & & $\psi_{t}^{2}$ & & $r_{t}$ & & $\rho_{I, t}$ & $\rho_{H, t}$ \\
\hline \multicolumn{11}{|c|}{ Short-run } \\
\hline & $\alpha_{0}$ & $(L) \alpha$ & $(L) \omega_{\psi}$ & & $(L) \omega_{\psi^{2}}$ & & $(L) \omega_{r}$ & & $(L) \omega_{\rho_{I}}$ & $(L) \omega_{\rho_{H}}$ \\
\hline \multirow[t]{2}{*}{$\operatorname{Cocoa}^{a}$} & 0.0013 & $-0.2011^{*}$ & $0.1952 * *$ & & $-0.0653 * *$ & & 0.1982 & & $0.1547 *$ & -0.1931 *** \\
\hline & $(0.002)$ & $(0.114)$ & $(0.084)$ & {$[3]$} & $(0.031)$ & [3] & $(0.129)$ & [2] & $(0.087)$ & $(0.040)$ \\
\hline \multirow[t]{2}{*}{ Coffee } & 0.0003 & $-0.2779 * * *$ & $0.1306^{* *}$ & & -0.0384 & & 0.0851 & & $0.2466 * * *$ & -0.2719 *** \\
\hline & $(0.001)$ & $(0.080)$ & $(0.075)$ & & $(0.050)$ & & $(0.149)$ & & $(0.087)$ & $(0.053)$ \\
\hline \multirow[t]{2}{*}{ Cotton } & -0.0008 & 0.1143 & $0.1171 * *$ & & $-0.0370 * * *$ & & -0.3216 & & 0.0688 & $-0.4591 * * *$ \\
\hline & $(0.004)$ & $(0.087)$ & $(0.050)$ & {$[3]$} & $(0.014)$ & [3] & $(0.517)$ & & $(0.252)$ & $(0.120)$ \\
\hline \multicolumn{11}{|c|}{ Long-run } \\
\hline & & $\phi$ & $\gamma_{\psi}$ & & $\gamma_{\psi^{2}}$ & & $\gamma_{r}$ & & $\gamma_{\rho_{I}}$ & $\gamma_{\rho_{H}}$ \\
\hline \multirow[t]{2}{*}{$\operatorname{Cocoa}^{a}$} & & $-0.2339 * * *$ & - & & - & & $0.1209 * * *$ & & $0.9278 * * *$ & - \\
\hline & & $(0.061)$ & & & & & {$[12.01]^{b}$} & & {$[11.55]^{\mathrm{b}}$} & \\
\hline
\end{tabular}

Note: Model estimated for 2007:M1-2017:M7 to allow enough room for appropriate lag selection. Standard errors in parentheses. Lag length

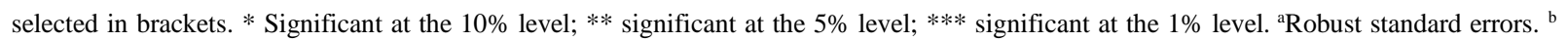
Long-run coefficients are recovered as the ratio between $\hat{\gamma}$ and the absolute value of $\hat{\phi}$. Wald test statistic of insignificance of the long run coefficient following a chi square distribution under the null in brackets. 
Table 2. Estimation of equation (6) with $y_{t}=\beta_{j, t}, j=\{S, C, W\}$

\begin{tabular}{|c|c|c|c|c|c|c|c|c|c|c|}
\hline & & Constant & $y_{t}$ & $\psi_{t}$ & $\overline{\psi_{t}^{2}}$ & & $r_{t}$ & $\rho_{I, t}$ & $\rho_{H, t}$ & \\
\hline \multicolumn{11}{|c|}{ Slope Factor } \\
\hline \multirow{7}{*}{$\frac{\pi}{\pi}$} & \multirow{3}{*}{ Cocoa } & $\alpha_{0}$ & $(L) \alpha$ & $(L) \omega_{\psi}$ & $(L) \omega_{\psi^{2}}$ & & $(L) \omega_{r}$ & $(L) \omega_{\rho_{I}}$ & $(L) \omega_{\rho_{H}}$ & \\
\hline & & 0.0005 & $-0.3538 * * *$ & $-0.5571 * * *$ & $0.2016^{* * *}$ & & 0.2227 & $-0.6369 * *$ & $0.4882 * * *$ & \\
\hline & & $(0.003)$ & $(0.073) \quad[1]$ & $(0.178)$ & $(0.070)$ & [4] & $(0.214)$ & $(0.251)$ & $(0.101)$ & \\
\hline & Coffee & -0.0014 & $-0.3455^{* * *}$ & 0.1664 & $-0.2792 * *$ & & -0.2643 & $-0.7956^{* * *}$ & $0.9842 * * *$ & \\
\hline & & $(0.004)$ & $(0.069) \quad[1]$ & $(0.213)$ & $(0.143)$ & {$[1]$} & $(0.429)$ & $(0.248)$ & $(0.156)$ & \\
\hline & Cotton & 0.0050 & $0.1535^{*}$ & $-0.2874 * *$ & $0.0915^{* * *}$ & & $2.5195^{* *}$ & -0.2124 & $0.8740^{* * *}$ & \\
\hline & & $(0.009)$ & $(0.087) \quad[1]$ & $(0.106)$ & $(0.030)$ & {$[3]$} & $(1.126)$ & $(0.535)$ & $(0.257)$ & \\
\hline \multirow{3}{*}{ 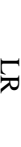 } & \multirow{3}{*}{ Cocoa } & & $\phi$ & $\gamma_{\psi}$ & $\gamma_{\psi^{2}}$ & & $\gamma_{r}$ & $\gamma_{\rho_{I}}$ & $\gamma_{\rho_{H}}$ & \\
\hline & & & $-0.1631 * * *$ & - & - & & - & $-2.6495 * * *$ & - & \\
\hline & & & $(0.048)$ & & & & & {$[7.868]^{\mathrm{b}}$} & & \\
\hline \multicolumn{11}{|c|}{ Curvature Factor } \\
\hline \multirow{7}{*}{$\approx$} & & $\alpha_{0}$ & $(L) \alpha$ & $(L) \omega_{\psi}$ & $(L) \omega_{\psi^{2}}$ & & $(L) \omega_{r}$ & $(L) \omega_{\rho_{I}}$ & $(L) \omega_{\rho_{H}}$ & \\
\hline & Cocoa & $-0.0283^{* *}$ & $-0.2622 * * *$ & $0.6779 *$ & $-0.2546^{*}$ & & $-1.1816^{* *}$ & -0.1109 & $0.4031^{*}$ & \\
\hline & & $(0.011)$ & $(0.085) \quad[1]$ & $(0.376)$ & $(0.147)$ & & $(0.463)$ & $(0.528)$ & $(0.229)$ & \\
\hline & Coffee & -0.0028 & $-0.3408 * * *$ & -0.5034 & 0.1380 & & -0.6459 & $-1.1329 * *$ & $1.0907 * * *$ & \\
\hline & & $(0.007)$ & $(0.081)$ & $(0.396)$ & $(0.266)$ & & $(0.790)$ & $(0.455)$ & $(0.282)$ & \\
\hline & Cotton $^{\mathrm{a}}$ & 0.0033 & - & $0.6716 * *$ & $-0.1427 * *$ & & $2.1523 * *$ & -0.5860 & $1.2125^{* * *}$ & \\
\hline & & $(0.021)$ & & $(0.254)$ & $(0.074)$ & & $(2.606)$ & (1.247) & $(0.600)$ & \\
\hline \multirow{3}{*}{$\frac{\pi}{\pi}$} & \multirow{3}{*}{ Cocoa } & & $\phi$ & $\gamma_{\psi}$ & $\gamma_{\psi^{2}}$ & & $\gamma_{r}$ & $\gamma_{\rho_{I}}$ & $\gamma_{\rho_{H}}$ & \\
\hline & & & $-0.3997 * * *$ & - & - & & $-0.6658 * * *$ & - & $1.1624 * * *$ & \\
\hline & & & $(0.089)$ & & & & {$[18.22]^{\mathrm{b}}$} & & {$[11.96]^{\mathrm{b}}$} & \\
\hline & \multicolumn{10}{|c|}{ Wave Factor } \\
\hline \multirow{7}{*}{$\cong$} & & $\alpha_{0}$ & $(L) \alpha$ & $(L) \omega_{\psi}$ & $(L) \omega_{\psi^{2}}$ & & $(L) \omega_{r}$ & $(L) \omega_{\rho_{I}}$ & $(L) \omega_{\rho_{H}}$ & \\
\hline & $\mathrm{Cocoa}^{\mathrm{a}}$ & 0.0003 & - & $0.0383^{* *}$ & $-0.0140 * *$ & & -0.0450 & $0.0460^{*}$ & $0.0177 * *$ & \\
\hline & & $(0.000)$ & & $(0.015)$ & $(0.006)$ & {$[1]$} & $(0.018)$ & $(0.020)$ & $(0.008)$ & [1] \\
\hline & Coffee $^{a}$ & 0.0017 & $-0.2965^{* *}$ & $0.0208 * *$ & $-0.0157 * * *$ & & 0.0199 & $0.0387 * *$ & $-0.0242 * *$ & \\
\hline & & $(0.001)$ & $(0.082)$ & (0.009) & $(0.006)$ & [3] & $(0.035)$ & $(0.019)$ & $(0.011)$ & \\
\hline & Cotton $^{\mathrm{a}}$ & 0.0003 & - & $0.0318^{* *}$ & $-0.0089 * *$ & & $0.1540 * * *$ & -0.0276 & $-0.0388 *$ & \\
\hline & & $(0.001)$ & & $(0.012)$ & $(0.003)$ & {$[4]$} & $(0.123)$ & $(0.062)$ & $(0.027)$ & [1] \\
\hline \multirow{5}{*}{ 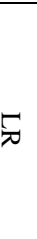 } & & & $\phi$ & $\gamma_{\psi}$ & $\gamma_{\psi^{2}}$ & & $\gamma_{r}$ & $\gamma_{\rho_{I}}$ & $\gamma_{\rho_{H}}$ & \\
\hline & $\mathrm{Cocoa}^{\mathrm{a}}$ & & $-0.6812 * * *$ & - & - & & $0.0075 * * *$ & $0.0495^{* * *}$ & - & \\
\hline & & & $(0.079)$ & & & & {$[6.662]^{\mathrm{b}}$} & {$[8.735]^{\mathrm{b}}$} & & \\
\hline & Coffee $^{a}$ & & $-0.2998 * * *$ & $-0.0306^{* *}$ & $0.0198 * * *$ & & - & $0.1185^{* *}$ & - & \\
\hline & & & $(0.078)$ & {$[6.333]^{\mathrm{b}}$} & {$[7.190]^{\mathrm{b}}$} & & & {$[5.438]^{\mathrm{b}}$} & & \\
\hline
\end{tabular}

Note: Model estimated for 2007:M1-2017:M7 to allow enough room for appropriate lag selection. Standard errors in parentheses. Lag length selected in brackets. * significant at the $1 \%$ level; ** significant at the $5 \%$ level; *** significant at the $1 \%$ level. ${ }^{\text {a }}$ Robust standard errors. ${ }^{\mathrm{b}}$ Long-run coefficients are recovered as the ratio between $\hat{\gamma}$ and the absolute value of $\hat{\phi}$. Wald test statistic of insignificance of the long run coefficient following a Chi Square distribution under the Null in brackets. SR: short-run; LR: long-run. 


\section{Figures}

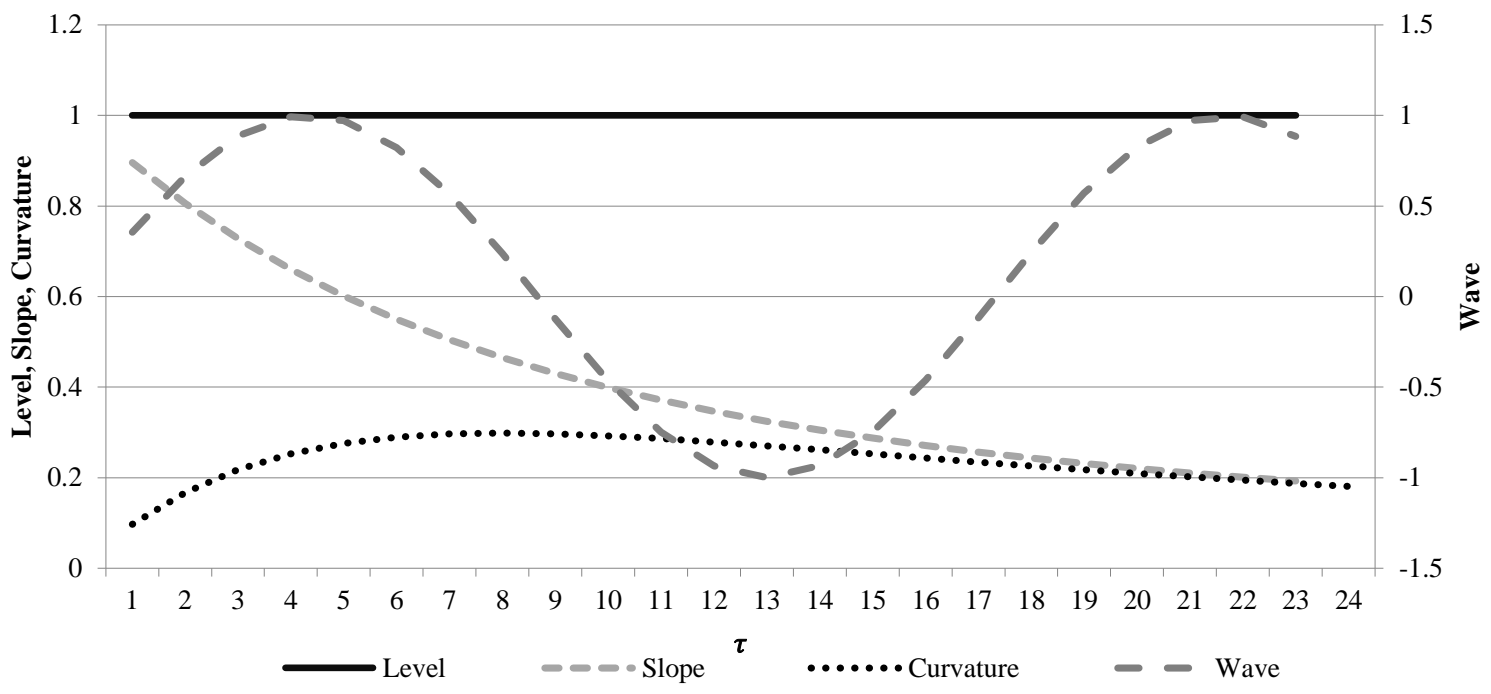

Figure 1. Nelson-Siegel factor loadings for $L, S, C, W$ in equation (5)

Note: $\lambda$ is fixed at 0.2242 , so that the curvature factor has its maximum at the 8 th month, where the wave factor has its turning point. 

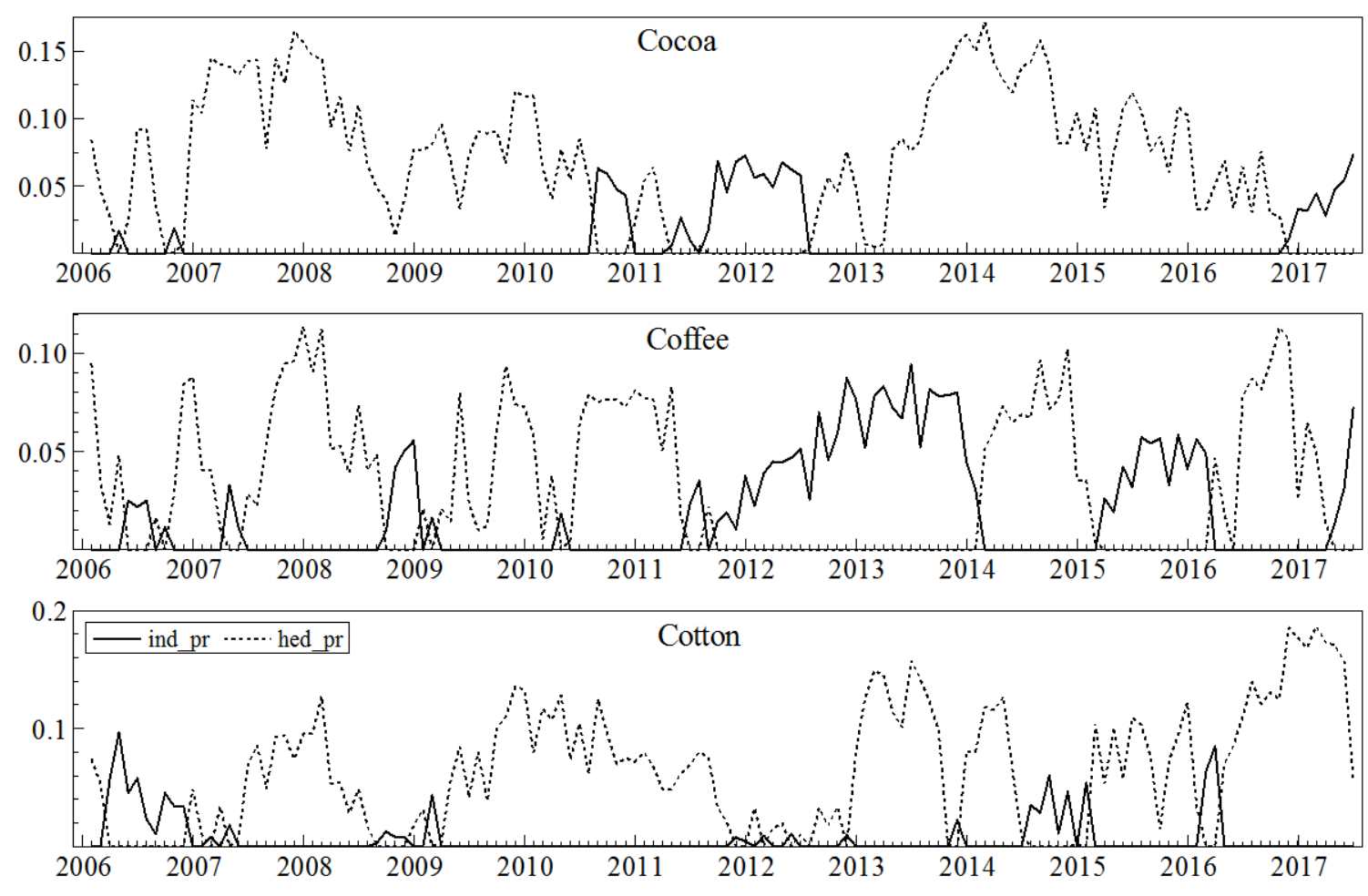

Figure 2. Index $\rho_{I, t}$ and hedging $\rho_{H, t}$ pressure from equation (7) 

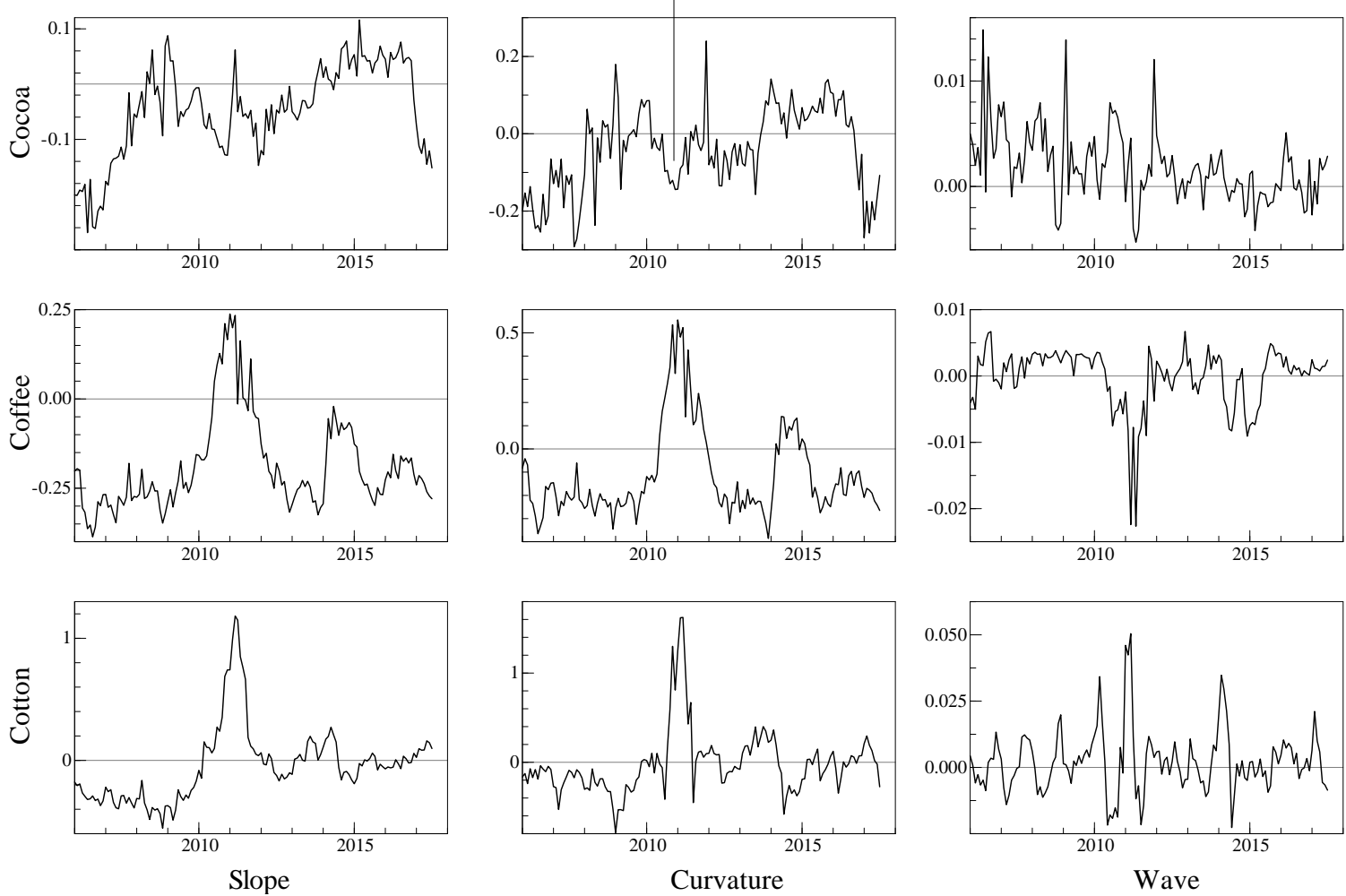

(A) Slope $\beta_{t, S}$, curvature $\beta_{t, C}$, and wave $\beta_{t, W}$ factor scores
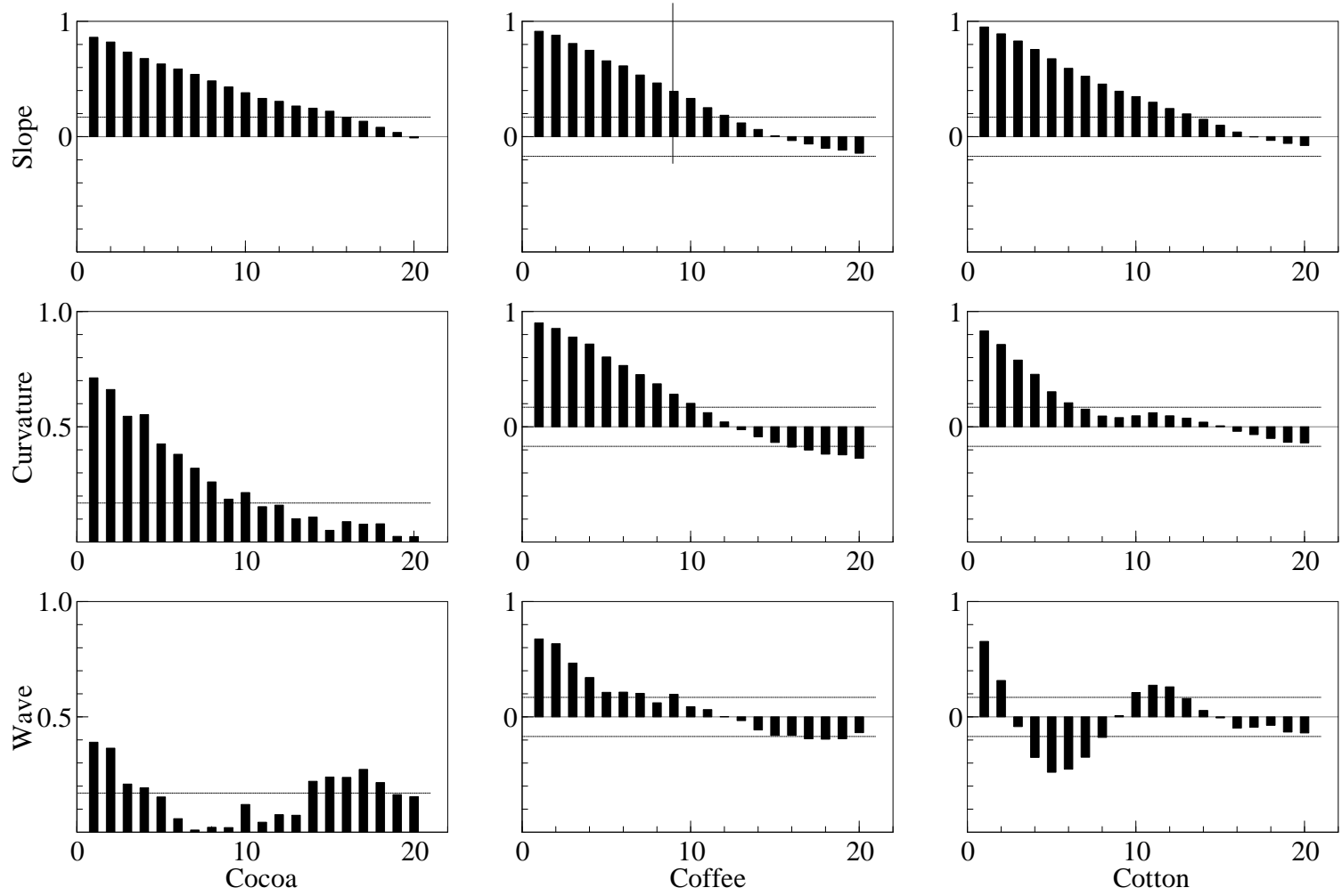
(B) Autocorrelation functions of the slope $\beta_{t, S}$, curvature $\beta_{t, C}$, and wave $\beta_{t, W}$ factor scores

Figure 3. Factor scores and autocorrelation function from equation (5) 